Check for updates

Cite this: Chem. Commun., 2021, 57,13146

Received 26th October 2021 Accepted 11th November 2021

DOI: $10.1039 / \mathrm{d} 1 \mathrm{cc} 06034 a$

rsc.li/chemcomm

\section{Tetra- and hexanuclear string complexes of the coinage metals $\dagger$}

\author{
Milena Dahlen, ${ }^{a}$ Tim P. Seifert, ${ }^{a}$ Sergei Lebedkin, ${ }^{b}$ Michael T. Gamer, (D) ${ }^{a}$ \\ Manfred M. Kappes (iD bc and Peter W. Roesky (D) *a
}

\begin{abstract}
Reaction of the PNNP ligand system $N, N^{\prime}$-bis[(2-diphenylphosphino) phenyl]formamidinate (dpfam) featuring different coordination compartments with $[\mathrm{AuCl}(\mathrm{tht})],[\mathrm{CuMes}]_{5},[\mathrm{AgMes}]_{4}$, or $\left[\mathrm{AuC}_{6} \mathrm{~F}_{5}(\mathrm{tht})\right]$ (tht = tetrahydrothiophene) resulted in tetranuclear homo- and heterometallic coinage metal complexes, as well as a hexanuclear gold complex. All of them feature a metal string conformation. Photophysical investigation revealed a significant dependence of the photoluminescence properties on the metal composition. Below $100 \mathrm{~K}$, the PL efficiency of three compounds approaches nearly $100 \%$.
\end{abstract}

A close arrangement of metal cations (below the sum of their van-der-Waals radii) is commonly entitled 'metallophilicity' - a concept which meanwhile includes a large variety of metal compositions. $^{1-3}$ As coinage metal complexes in particular often feature the latter, they have been the subject of intense research for several decades aiming towards a better understanding of the phenomenom. ${ }^{4}$ They are furthermore known to influence and yield interesting photophysical properties. ${ }^{2,5,6}$ For heavy metals, such as gold, an enhanced spin-orbit coupling additionally favours an intersystem crossing (ISC) mechanism, often leading to a phosphorescence-based emission. ${ }^{5}$ Convenient tuning of these photoluminescence properties is demanded in various fields of application. While molecular multinuclear coinage metal compounds are known for their tendency to form dense cluster cages, ${ }^{7}$ also an elongated or linear (metal string) arrangement of four and more metal centres is of interest. ${ }^{8-10}$ These so-called metal string complexes find application as constructional units for molecularscale wires. ${ }^{11}$ To preserve cluster formation and to result in a

\footnotetext{
${ }^{a}$ Institute of Inorganic Chemistry, Karlsruhe Institute of Technology (KIT), Engesserstr. 15, Karlsruhe 76131, Germany.E-mail: roesky@kit.edu

${ }^{b}$ Institute of Nanotechnology Karlsruhe Institute of Technology (KIT) Hermann-von-Helmholtz-Platz 1, Eggenstein-Leopoldshafen 76344, Germany ${ }^{c}$ Institute of Physical Chemistry Karlsruhe Institute of Technology (KIT) Fritz-Haber-Weg 2, Karlsruhe 76131, Germany

$\dagger$ Electronic supplementary information (ESI) available. CCDC 2117887-2117890. For ESI and crystallographic data in CIF or other electronic format see DOI: 10.1039/d1cc06034a
}

linear arrangement, the coinage metal ions need to be assembled on a suitable ligand.

In this context, the PNNP ligand dpfam ( $N, N^{\prime}$-bis[(2-diphenylphosphino)phenyl]formamidinate $)^{12}$ was already proved suitable to provide a scaffold for selective synthesis of heterometallic multinuclear complexes by others and our group., ${ }^{9,12-14}$ Up to now, symmetrically tri- and tetra nuclear dpfam coinage metal complexes were obtained as ions, which were charge balanced by weakly coordinating anions, e.g. $\mathrm{PF}_{6}{ }^{-}$or $\mathrm{BF}_{4}{ }^{-}$. Due to this strategy, the metal cations were exclusively coordinated by the donor atoms of the ligand ( $\mathrm{N}$ and/or $\mathrm{P}$ ). ${ }^{9,14}$ In contrast to the previous study, we now employed precursors, in which the counterion is tightly bound to the metal and thus not replaced during the course of reaction. As result, a larger variety of new complexes concomitant with the selective formation of neutral tetra- and hexanuclear complexes was obtained. Following this strategy, reaction of the potassium salt Kdpfam $^{14}$ with four equivalents of $[\mathrm{AuCl}(\mathrm{tht})]$ (tht $=$ tetrahydrothiophene) resulted in the tetranuclear gold complex $\left[\mathrm{dpfam}(\mathrm{AuCl})_{3}\right.$ $\mathrm{Au}(\mathrm{tht})]$ (1) (Scheme 1).

Compound $\mathbf{1}$ is only stable in the mother liquor with an excess of tetrahydrothiophene but decompose within minutes upon drying. The mechanism of decomposition is not clear, it might, however, be related to a loss of the more labile ligand tht. ${ }^{15}$ The molecular structure in the solid state revealed a trinuclear gold chain with a small intermetallic angle of 98.45(2) ${ }^{\circ}$ and aurophilic contacts of 2.9579(8) $\AA$ (Au1-Au2) and 2.9529(9) $\AA$ (Au2-Au2). ${ }^{16}$ An intermetallic contact to the fourth gold atom, however, seems to be hindered (distance
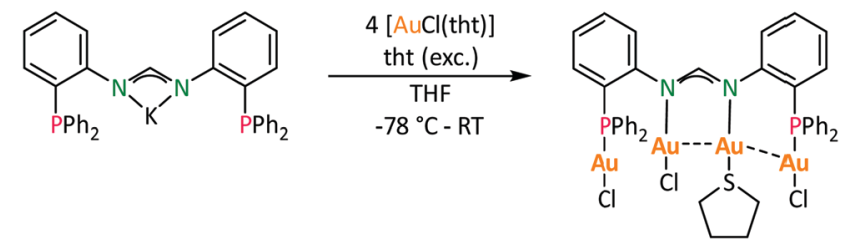

Scheme 1 Synthesis of the homometallic tetranuclear gold complex [dpfam(AuCl) 3 Au(tht)] (1). 


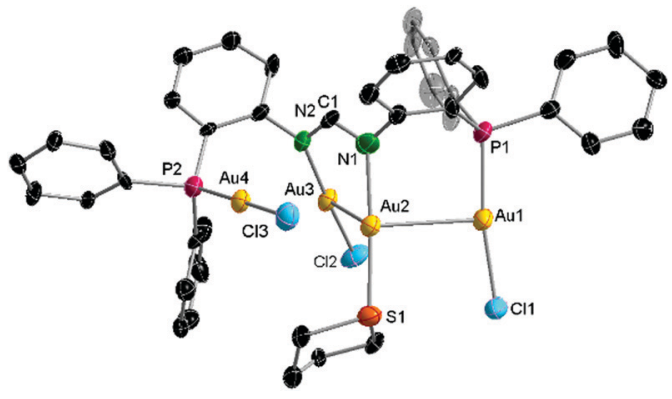

Fig. 1 Molecular structure of the homometallic tetranuclear complex [dpfam(AuCl) 3 Au(tht)] (1) in the solid state. Hydrogen atoms and cocrystallized solvent molecules are omitted for clarity. Only one molecule of the asymmetric unit is displayed. Selected bond lengths and angles can be found in the ESI $†$ (Section S5).

$\mathrm{Au} 3-\mathrm{Au} 4$ 4.1704(8) $\AA$ ) and the respective $\mathrm{Au}-\mathrm{Cl}$ unit is tilted away (Fig. 1). While all neutral charged donor atoms of the dpfam ligand coordinate to an $\mathrm{Au}-\mathrm{Cl}$ fragment each (generated from [AuCl(tht)] by loss of tht), the anionic amidinate N-atom binds to an $\mathrm{Au}(\mathrm{tht})$ entity (generated from $[\mathrm{AuCl}(\mathrm{tht})]$ by precipitation of $\mathrm{KCl}$ ). A similar structural motif was observed earlier, e.g., by Braunstein, Danopoulos et al. who also used $[\mathrm{AuCl}($ tht $)]$ as metal source. ${ }^{17}$ Despite the different coordination modes, the $\mathrm{Au}-\mathrm{N}$ bond lengths are almost identical (N1-Au2 2.096(13) $\AA$, N2-Au3 2.019(11) $\AA$ ) as are the $\mathrm{C}-\mathrm{N}$ distances in the amidinate backbone (N1-C1 1.30(2) $\AA$, C1-N2 1.33(2) ̊̊).

In order to incorporate more stable substituents on heterometallic complexes, in situ synthesized bimetallic [ $\left.\mathrm{dpfam}_{2} \mathrm{Au}_{2}\right]$ $(\mathbf{I})^{14}$ was reacted with mesityl copper $[\mathrm{CuMes}]_{5}$ or mesityl silver $[\mathrm{AgMes}]_{4}$ (Scheme 2). The tetranuclear compound [dpfam ${ }_{2} \mathrm{Cu}_{2}\left(\right.$ AuMes $\left._{2}\right]$ (2) was obtained as bright orange crystals (yield 36\%) after crystallization from THF and $n$-pentane. It shows intense orange luminescence upon UV light excitation (Fig. 5) with a high quantum yield of approximately $35 \%$ at ambient temperature. The molecular structure in the solid state revealed a ligand exchange: the mesityl moiety is moved from the copper to the gold cation, resulting in a dicopper bisamidinate complex with adjacent P-Au-mesityl units. ${ }^{18-20}$ The four metal atoms in 2 form an $\mathrm{Au}-\mathrm{Cu}-\mathrm{Cu}-\mathrm{Au}$ zigzag chain with an angle of $111.62(2)^{\circ}$ and intermetallic distances of 2.7939(9) $\AA$ $(\mathrm{Cu}-\mathrm{Cu})$ and $2.9960(4) \AA(\mathrm{Au}-\mathrm{Cu})$, all within the range of metallophilic interactions. ${ }^{10}$ The copper atoms each are coordinated by two nitrogen atoms of the amidinate units and the phosphine moiety in an almost $T$-shaped geometry. Additional metallophilic contacts to gold and another copper atom complete the distorted trigonal bipyramidal coordination sphere (Fig. 2). Furthermore, most aromatic groups are arranged in a parallel-displaced fashion with distances of $\sim 4 \AA$ (see ESI, $\dagger$ Fig. S4-1), which might be attributed to $\pi$-stacking. ${ }^{21}$ The $\mathrm{P}-\mathrm{Au}-$ mesityl and the $\mathrm{N}-\mathrm{Cu}-\mathrm{N}$ moiety show very similar angles $167.67(10)^{\circ}$ and $165.63(12)^{\circ}$, respectively. No interpretable NMR spectra could be obtained due to low solubility or decomposition. The corresponding silver analogue 3 was obtained similarly to 2 from $\mathrm{THF} / n$-pentane to give pale amber coloured

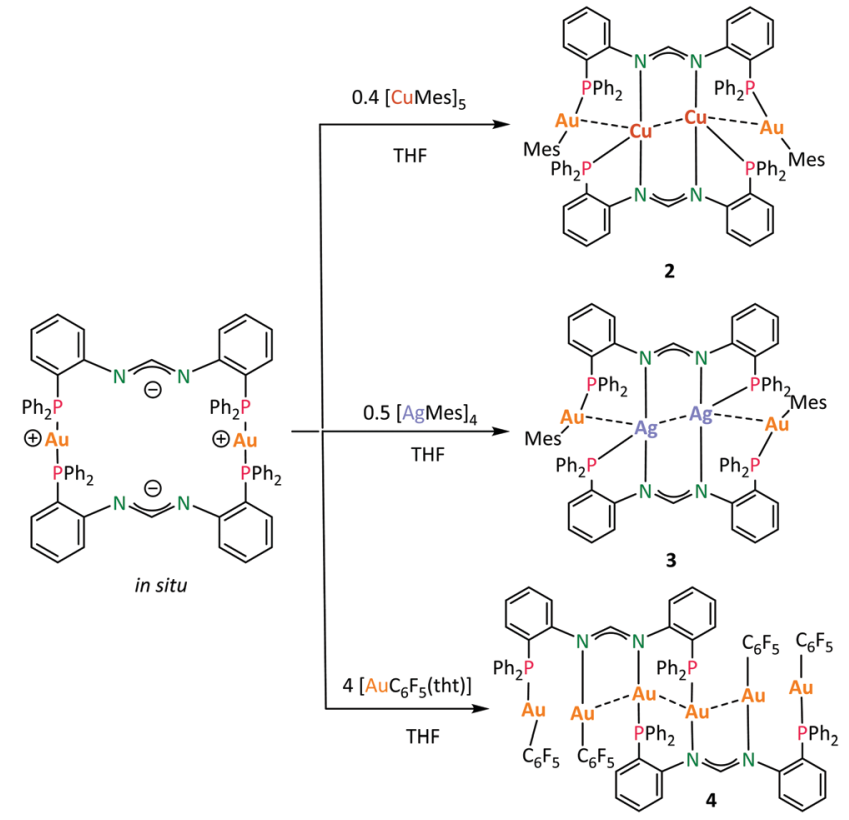

Scheme 2 Synthetic strategy towards the heterometallic complexes 2 and 3 as well as homometallic complex 4. Mes $=$ mesityl, $\mathrm{C}_{6} \mathrm{~F}_{5}=$ pentafluorophenyl.

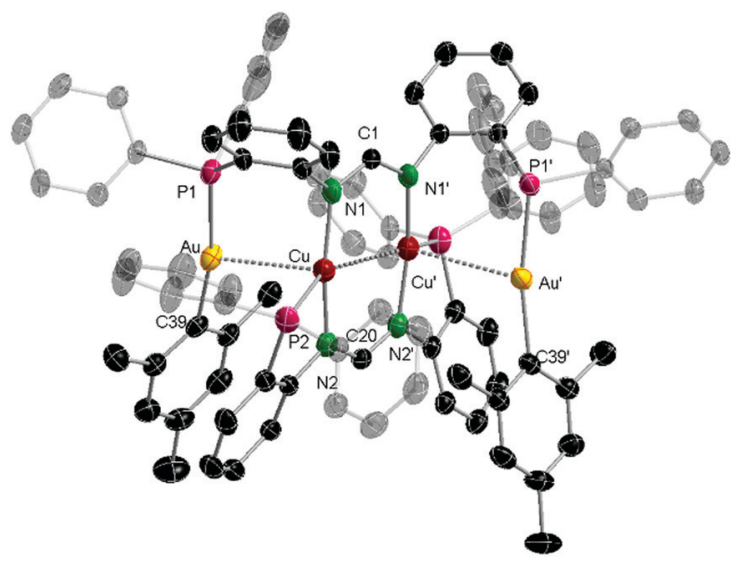

Fig. 2 Molecular structure of the tetranuclear bimetallic complex 2 in the solid state. Hydrogen atoms and co-crystallized solvent molecules are omitted for clarity. Atoms labelled with a dash are symmetry generated. Selected bond lengths and angles can be found in the ESI† (Section S5).

crystals (white powder when dried) in yields up to $33 \%$ (Scheme 2).

Complex 3 demonstrates an intense blueish luminescence when excited with UV irradiation. The solid state structure revealed a tetranuclear $\mathrm{Au}-\mathrm{Ag}-\mathrm{Ag}-\mathrm{Au}$ chain and a similar ligand exchange as seen for 2 (Fig. 3). However, in contrast to its copper derivative $\left(D_{3 \mathrm{~d}}\right.$ symmetry, $C_{2}$-axis along $\left.\mathrm{C} 1-\mathrm{C} 1^{\prime}\right)$, the mesityl gold units are located on the opposing ligands ( $C_{\mathrm{i}}$ symmetry) (see also ESI, $\dagger$ Fig. S4-5), which might be attributed to the larger ion radius of silver.

The tetranuclear chain features intermetallic interactions with bond lengths of 2.9756(3) $\AA(\mathrm{Au}-\mathrm{Ag})$ and 2.9009(5) $\AA$ 


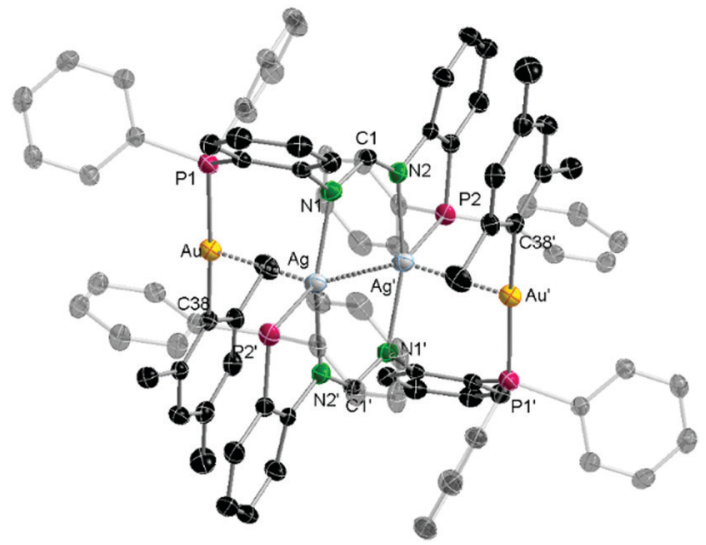

Fig. 3 Molecular structure of the tetranuclear bimetallic complex $\mathbf{3}$ in the solid state. Hydrogen atoms and co-crystallized solvent molecules are omitted for clarity. Atoms labelled with a dash are symmetry generated. Selected bond lengths and angles can be found in the ESI $\dagger$ (Section S5).

$(\mathrm{Ag}-\mathrm{Ag})$ and an intermetallic angle of $102.197(13)^{\circ} .{ }^{22}$ As seen for 2 , the inner $\mathrm{Ag}$ atoms are in a nearly $T$-shaped trigonal coordination environment, each coordinated by two nitrogen atoms and one phosphine moiety. Additional metallophilic contacts result in an overall trigonal bipyramidal coordination (Fig. 3). The gold atoms are coordinated by one mesityl and one phosphine moiety in a nearly linear fashion $\left(173.80(10)^{\circ}\right)$. Like for 2, no useful NMR spectroscopic data could be obtained for 3 due to low solubility.

Synthesis of the tetranuclear gold analogue was attempted by in situ generation of mesityl gold (from [AgMes] $]_{4}$ and [AuCl(tht)]) which was subsequently added to the digold metalloligand. However, no suitable product could be isolated, leaving the synthesis of the respective $\left[\operatorname{dpfam}_{2} \mathrm{Au}_{2}\left(\mathrm{AuMes}_{2}\right]\right.$ compound unsuccessful.

Finally, hexanuclear $\left[\mathrm{dpfam}_{2} \mathrm{Au}_{2}\left(\mathrm{AuC}_{6} \mathrm{~F}_{5}\right)_{4}\right](4)$ was obtained analogously to 2 and 3 by reacting metalloligand [dpfam ${ }_{2} \mathrm{Au}_{2}$ ] (I) with $\left[\mathrm{AuC}_{6} \mathrm{~F}_{5}(\mathrm{tht})\right]$ (Scheme 2). Crystallization from diethyl ether yielded colourless crystals expressing an intense bluegreenish luminescence at room temperature upon excitation with a UV lamp (Fig. 5). Investigation of the molecular structure in the solid state revealed a rare discrete $\mathrm{Au}_{6}$ chain $^{23,24}$ with the inner four atoms being connected by aurophilic interactions and the outer $\mathrm{P}-\mathrm{Au}-\mathrm{C}_{6} \mathrm{~F}_{5}$ moieties being tilted apart in opposite directions from the chain ( $C_{2 \mathrm{~h}}$ symmetry), similar to 1 (Fig. 4). The ligands are displaced against each other and only connected via two $\mathrm{N}-\mathrm{Au}-\mathrm{P}$ bridges $\left(176.7(2)^{\circ}\right)$. The remaining nitrogen and phosphorous coordination sites each coordinate an $\mathrm{Au}-\mathrm{C}_{6} \mathrm{~F}_{5}$ moiety (C38-Au2-N2 170.9(3) ${ }^{\circ}$, C44-Au3-P2 $\left.170.5(2)^{\circ}\right)$. $\mathrm{Au}-\mathrm{Au}$ distances of the $\mathrm{Au}_{4}$ chain are within the range of aurophilic contacts. ${ }^{3,24}$ For Au2-Au3, a distance of 4.7038(6) ^ probably excludes an interaction. As for 2 und 3, pronounced intra- and intermolecular aromatic stacking can be observed between the $\mathrm{C}_{6} \mathrm{~F}_{5}$ as well as the phenyl moieties of the ligands (see ESI, $\dagger$ Fig. S4-9). ${ }^{25}$ Compound 4 is partly soluble in THF and DMSO but shows uninterpretable resonances in NMR spectra probably due to disproportionation or decomposition.

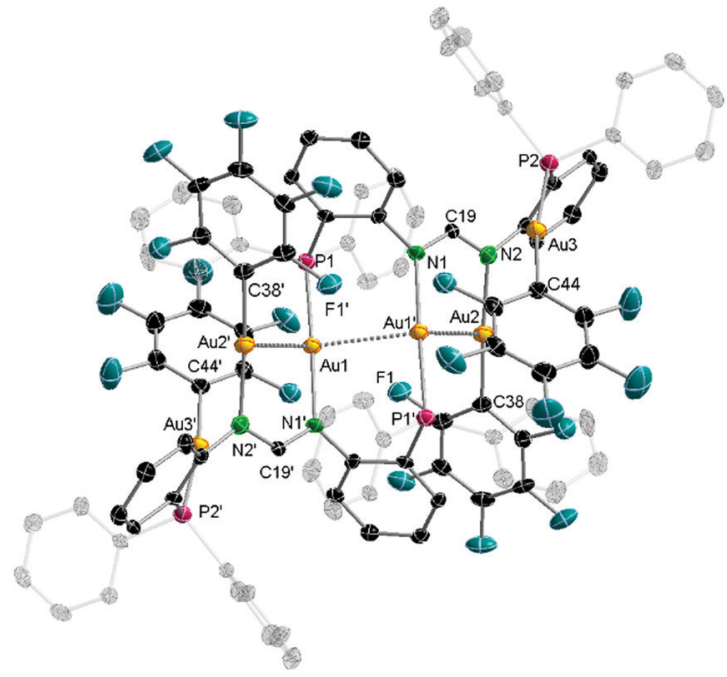

Fig. 4 Molecular structure of the homometallic hexanuclear complex 4 in the solid state. Hydrogen atoms and co-crystallized solvent molecules are omitted for clarity. Atoms labelled with a dash are symmetry generated. Selected bond lengths and angles can be found in the ESI $\dagger$ (Section S5).

In photoluminescence (PL) spectroscopy, all isolated solid compounds (2-4) show a broad emission, both at ambient and low temperatures, with a maximum at $600 \mathrm{~nm}, 482 \mathrm{~nm}$ and $465 \mathrm{~nm}$, respectively (at $295 \mathrm{~K}$, Fig. 5). A significant bathochromic shift both in the emission and excitation spectra of the copper-containing compound $\mathbf{2}$, when compared to $\mathbf{3}$ and $\mathbf{4}$, can be tentatively attributed to contribution of the d-orbitals of copper in line with the results previously reported for other compounds. ${ }^{26}$ The PL of $\mathbf{2 - 4}$ is phosphorescence as indicated by microsecond-long emission decays, measured with a nanosecond-pulsed $\mathrm{N}_{2}$-laser excitation at $337 \mathrm{~nm}$. Phosphorescence lifetimes at $20 \mathrm{~K}$ were determined to be $310 \mu$ s for $2, c a$.

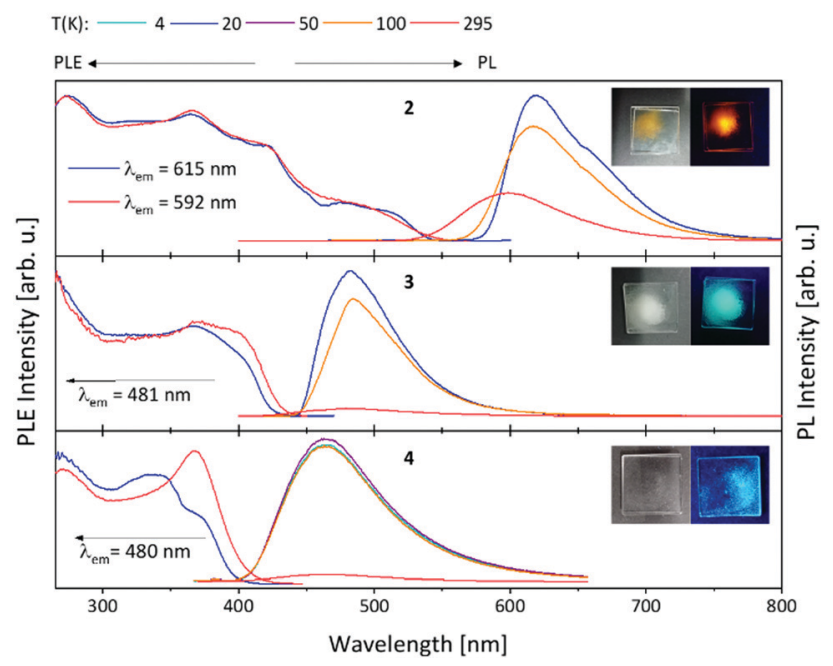

Fig. 5 Photoluminescence emission (PL) and excitation (PLE) spectra of compounds $\mathbf{2 - 4}$ at different temperatures. The PL spectra were excited at $\lambda_{\text {exc }}=350 \mathrm{~nm}$ (2 and 3) or $340 \mathrm{~nm}$ (4). PLE was recorded at the depicted wavelengths $\left(\lambda_{\mathrm{em}}\right)$. Photographs show the sample at daylight (left) and under UV light ( $\lambda_{\mathrm{exc}}=365 \mathrm{~nm}$, right). 
$320 \mu$ s for 3 (average lifetime of the biexponential decay), and $89 \mu$ s for 4. At room temperature, the lifetimes decline, roughly correlating with the decrease in PL intensity. While there is still a significant signal at $295 \mathrm{~K}$ for 2 , visible emission broadens and strongly decreases for 3 and 4. Quantum yields were determined at room temperature using an integrating sphere to be approximately $35 \%$ for $2,5 \%$ for 3 and $7 \%$ for 4 , excited at $350 \mathrm{~nm}$. Note that at temperatures below $100 \mathrm{~K}$, the PL efficiency of 2-4 approaches nearly $100 \%$ as estimated from the temperature-dependent PL spectra (Fig. 5).

In summary, we report a systematic and rational approach to establish homo- and heterometallic coinage metal string complexes with the maximum amount of metal atoms possibly fitting in the used PNNP ligand scaffold. In this course, we presented three new tetranuclear coinage metal complexes out of which two are heterometallic and feature a particular ligand exchange. Additionally, a hexanuclear gold complex was presented. Complexes 2-4 were also subject of solid state photophysical investigations as they demonstrate relatively intense luminescence at ambient temperature. Below $100 \mathrm{~K}$, the PL efficiency of 2-4 approaches nearly $100 \%$.

DFG-funded transregional collaborative research center SFB/ TRR 88 "Cooperative effects in homo- and heterometallic complexes (3MET)" (C3 and C7) supported this work. Thanks to Dr C. Schoo for X-ray data refinement. M. D. thanks the "Fonds der Chemischen Industrie" for the fellowship (No. 103581).

\section{Conflicts of interest}

There are no conflicts to declare.

\section{Notes and references}

1 S. Raju, H. B. Singh and R. J. Butcher, Dalton Trans., 2020, 49, 9099-9117; M. Jansen, Angew. Chem., Int. Ed., 1987, 26, 1098-1110. 2 V. W.-W. Yam, V. K.-M. Au and S. Y.-L. Leung, Chem. Rev., 2015, 115, 7589-7728.

3 H. Schmidbaur and A. Schier, Chem. Soc. Rev., 2012, 41, 370-412.

4 H.-X. Zhang and C.-M. Che, Chem. - Eur. J., 2001, 7, 4887-4893; P. Pyykkö, Angew. Chem., Int. Ed., 2004, 43, 4412-4456; P. Pyykkö, J. Li and N. Runeberg, Chem. Phys. Lett., 1994, 218, 133-138; M. B. Brands, J. Nitsch and C. F. Guerra, Inorg. Chem., 2018, 57, 2603-2608; J. Li and P. Pyykkö, Chem. Phys. Lett., 1992, 197, 586-590; Q. Zheng, S. Borsley, G. S. Nichol, F. Duarte and S. L. Cockroft, Angew. Chem., Int. Ed., 2019, 58, 12617-12623; E. Andris, P. C. Andrikopoulos, J. Schulz, J. Turek, A. Růžička, J. Roithová and L. Rulíšek, J. Am. Chem. Soc., 2018, 140, 2316-2325; M. Jansen, J. Less-Common Met., 1980, 76, 285-292.

5 V. W.-W. Yam and E. Chung-Chin Cheng, in Photochemistry and photophysics of coordination compounds II, ed. V. Balzani, S. Campagna and A. Barbieri, Springer, Berlin, Heidelberg, 2007, vol. 281, pp. 269-309.

6 H. Schmidbaur and A. Schier, Angew. Chem., Int. Ed., 2015, 54, 746-784; T. P. Seifert, V. R. Naina, T. J. Feuerstein, N. D. Knöfel and P. W. Roesky, Nanoscale, 2020, 12, 20065-20088; V. W.-W. Yam and K. M.-C. Wong, Chem. Commun., 2011, 47, 11579-11592; C. E. Strasser and V. J. Catalano, J. Am. Chem. Soc., 2010, 132, 10009-10011; M. J. Calhorda, C. Ceamanos, O. Crespo, M. C. Gimeno, A. Laguna, C. Larraz, P. D. Vaz and M. D. Villacampa, Inorg. Chem., 2010, 49,
8255-8269; T. P. Seifert, S. Bestgen, T. J. Feuerstein, S. Lebedkin, F. Krämer, C. Fengler, M. T. Gamer, M. M. Kappes and P. W. Roesky, Dalton Trans., 2019, 48, 15427-15434; R. L. WhiteMorris, M. M. Olmstead, F. Jiang, D. S. Tinti and A. L. Balch, J. Am. Chem. Soc., 2002, 124, 2327-2336; A. L. Balch, Angew. Chem., Int. Ed., 2009, 48, 2641-2644.

7 L. Estévez, Dalton Trans., 2020, 49, 4797-4804; H. T. Al-Masri and A. A. Almejled, Z. Anorg. Allg. Chem., 2020, 646, 354-358; A. K. Gupta and A. Orthaber, Chem. - Eur. J., 2018, 24, 7536-7559; A. K. Ghosh and V. J. Catalano, Eur. J. Inorg. Chem., 2009, 1832-1843; H. de la Riva, M. Nieuwhuyzen, C. Mendicute Fierro, P. R. Raithby, L. Male and M. C. Lagunas, Inorg. Chem., 2006, 45, 1418-1420.

8 T. Tanase, R. Otaki, T. Nishida, H. Takenaka, Y. Takemura, B. Kure, T. Nakajima, Y. Kitagawa and T. Tsubomura, Chem. - Eur. J., 2014, 20, 1577-1596; D. Li, C.-M. Che, S.-M. Peng, S.-T. Liu, Z.-Y. Zhou and T. C. W. Mak, J. Chem. Soc., Dalton Trans., 1993, 189-194; P. Braunstein and A. A. Danopoulos, Chem. Rev., 2021, 121, 7346-7397.

9 M. Dahlen, E. H. Hollesen, M. Kehry, M. T. Gamer, S. Lebedkin, D. Schooss, M. M. Kappes, W. Klopper and P. W. Roesky, Angew. Chem., Int. Ed., 2021, 60, 23365-23372.

10 M. Stollenz, Chem. - Eur. J., 2019, 25, 4274-4298.

11 I. P. Liu, W. Z. Wang and S. M. Peng, Chem. Commun., 2009, 4323-4331; K. Krogmann, Angew. Chem., 1969, 81, 10-17; N. V. S. Harisomayajula, B.-H. Wu, D.-Y. Lu, T.-S. Kuo, I. C. Chen and Y.-C. Tsai, Angew. Chem., Int. Ed., 2018, 57, 9925-9929.

12 N. Tsukada, O. Tamura and Y. Inoue, Organometallics, 2002, 21, 2521-2528.

13 L. Wesemann, H. Schubert, H. Mayer, S. Wernitz and E.-K.-U. Tübingen, Germany Pat., DE10 2011079857A1, 2011; K.-S. Son, D. M. Pearson, S.-J. Jeon and R. M. Waymouth, Eur. J. Inorg. Chem., 2011, 4256-4261; S. Tanaka, A. Yagyu, M. Kikugawa, M. Ohashi, T. Yamagata and K. Mashima, Chemistry, 2011, 17, 3693-3709; Y. Yamaguchi, K. Yamanishi, M. Kondo and N. Tsukada, Organometallics, 2013, 32, 4837-4842; M. Dahlen, N. Reinfandt, C. Jin, M. T. Gamer, K. Fink and P. W. Roesky, Chem. - Eur. J., 2021, 27, 15128-15136.

14 M. Dahlen, M. Kehry, S. Lebedkin, M. M. Kappes, W. Klopper and P. W. Roesky, Dalton Trans., 2021, 50, 13412-13420.

15 S. Bestgen, C. Seidl, T. Wiesner, A. Zimmer, M. Falk, B. Köberle, M. Austeri, J. Paradies, S. Bräse, U. Schepers and P. W. Roesky, Chem. - Eur. J., 2017, 23, 6315-6322.

16 H. Schmidbaur and A. Schier, Chem. Soc. Rev., 2008, 37, 1931-1951. 17 P. Ai, M. Mauro, C. Gourlaouen, S. Carrara, L. De Cola, Y. Tobon, U. Giovanella, C. Botta, A. A. Danopoulos and P. Braunstein, Inorg. Chem., 2016, 55, 8527-8542.

18 T. J. Feuerstein, T. P. Seifert, A. P. Jung, R. Müller, S. Lebedkin, M. M. Kappes and P. W. Roesky, Chem. - Eur. J., 2020, 26, 16676-16682.

19 S. Bestgen, C. Schoo, C. Zovko, R. Köppe, R. P. Kelly, S. Lebedkin, M. M. Kappes and P. W. Roesky, Chem. - Eur. J., 2016, 22, 7115-7126.

20 H. G. Raubenheimer and H. Schmidbaur, Organometallics, 2012, 31, $2507-2522$.

21 S. Grimme, Angew. Chem., Int. Ed., 2008, 47, 3430-3434; C. A. Hunter and J. K. M. Sanders, J. Am. Chem. Soc., 1990, 112, 5525-5534.

22 S. Alvarez, Dalton Trans., 2013, 42, 8617-8636; M. Gil-Moles, M. Concepción Gimeno, J. M. López-de-Luzuriaga, M. Monge, M. E. Olmos and D. Pascual, Inorg. Chem., 2017, 56, 9281-9290.

23 T. Tanase, M. Chikanishi, K. Morita, K. Nakamae, B. Kure and T. Nakajima, Chem. - Asian J., 2015, 10, 2619-2623.

24 Y. Takemura, H. Takenaka, T. Nakajima and T. Tanase, Angew. Chem., Int. Ed., 2009, 48, 2157-2161.

25 R. Donamaría, V. Lippolis, J. M. López-de-Luzuriaga, M. Monge, M. Nieddu and M. E. Olmos, Dalton Trans., 2020, 49, 10983-10993.

26 S. Schäfer, M. T. Gamer, S. Lebedkin, F. Weigend, M. M. Kappes and P. W. Roesky, Chem. - Eur. J., 2017, 23, 12198-12209; C. Kiefer, S. Bestgen, M. T. Gamer, M. Kühn, S. Lebedkin, F. Weigend, M. M. Kappes and P. W. Roesky, Chem. - Eur. J., 2017, 23, 1591-1603. 